\title{
In halt.
}

Einleitung

I. Die Quellen des Traktates . . . . . . . . . . . . . . . . . 3

II. Die Datierung des Traktates . . . . . . . . . . . . . . . . 18

III. Der Inhalt des Traktates. . . . . . . . . . . . . . . . . . 23

IV. Die Korrespondenz zwischen Wibert und Anselm und der Traktat Widos in ihrer historischen Bedeutung . . . . . . . . . . . . . . . 39

Exkurs: Über dic Quellen der Geschichte der Jahre 1083 und 1084 . . . . 51

Fragmente des Schreibens Wiberts von Ravenna an Anselm von Lucca . . . 58 


\section{Verlag von VEIT \& COMP. in Leipzig. Historische Studien.}

Herausgegeben

von

W. Arndt, C. von Noorilen und G. Voigt in Leipzig, B. Erdmannsiörffer und E. Winkelmann in Heidelberg, W. Manrenbrecher und M. Ritter in Bonn, R. Panli und J. Weizsäeker in Güttingen, C. Varrentrapp in Marburg.

Erstes Heft: Das Königtum Günthers von Schwarzburg. Kin Beitrag zur Reichsgeschichte des XIV. Jahrlunderts. Von KarL Janson. Fingeleitet von J. WEIzsäcker. gr. 8. geh.

Zweites Heft: Wido von Ferrara, de scismate Hildebrandi. Fin Beitrag zur Geschichte des Investiturstreites. Von Konrad PanzKr. ' Fingeleitet von W. Maurenbrecher. gr. 8. geh. $\quad$ M. 1. 80.

Block, M., Handbuch der Statistik. Deutsche Ausgabe, zugleich als "Handbuch der Statistik des Deutschen Reichs" von Prof. Dr. H. von Scheel. gr. 8. geh.

I. 6. -

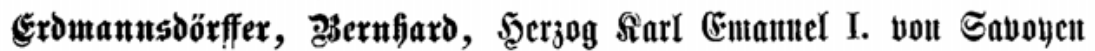

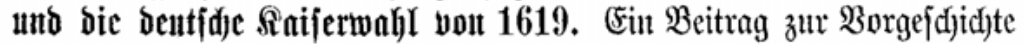
Des breiß̄igjährigen Sirieges. gr. 8 . geh.

M. 2. -

Hilgenfeld, Adolf, Die Lehninische Weissagung über die Mark Brandenburg, nebst der Weissagung von Benedietbenern üher Bayern. Untersucht, herausgegeben und erklärt. gr. 8. geh. M. 2.40.

Krusch, Bruno, Studien zur christlich-mittelalterlichen Chronologie. Der 84jährige Ostercyclus und seine Quellen. gr. 8. geh. M. 10.

Marii episcopi Aventicensis chronicon edidit Wilhelmus Arndt. gr. 8. geh.

M. $1 .-$

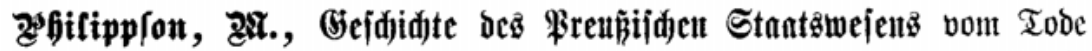

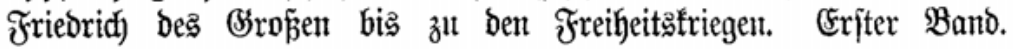
gr. 8. geh .

M. $10 .-$

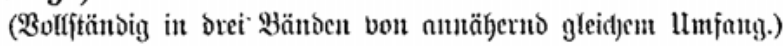

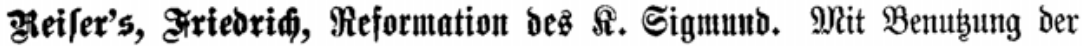
älteften beanofdjriften nebjt einer fritifajen Einleitung und einem erffä=

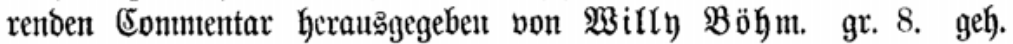

M. 7. 20.

Wittich, Karl, Struensee. gr. 8. geh.

M. 5. -

Wychgram, J., Albertino Mussato. Ein Beitrag zur italienischen Geschichte des vierzehnten Jahrhunderts. gr. 8. geh. M. 2. 40. 
